\title{
Neurodevelopmental Problems in Children at 9 Months of Age Associated with Neonatal Hypoxic-Ischemic Encephalopathy
}

\author{
Evelyn Mungyeh Mah"1,2, Seraphin Nguefack ${ }^{1,2}$, Hélène Kamo Selangai², Andréas Chiabi',2, \\ Mbassi Awa $^{2,3}$, Félicité Dongmo1,2, Mazou Ngou Temgoua ${ }^{2}$, Elie Mbonda1 \\ ${ }^{1}$ Affiliation Department of Pediatrics, Gyneco-Obstetric and Pediatric Hospital of Yaoundé, Yaoundé, Cameroon \\ ${ }^{2}$ Faculty of Medicine and Biomedical Sciences, University of Yaoundé I, Yaoundé, Cameroon \\ ${ }^{3}$ Mother and Child Center of the Chantal Biya Foundation, Yaoundé, Cameroon \\ Email: aminevelyn@yahoo.co.uk
}

How to cite this paper: Mah, E.M., Nguefack, S., Selangai, H.K., Chiabi, A., Awa, M., Dongmo, F., Temgoua, M.N. and Mbonda, E. (2017) Neurodevelopmental Problems in Children at 9 Months of Age Associated with Neonatal Hypoxic-Ischemic Encephalopathy. Open Journal of Pediatrics, 7, 98108.

https://doi.org/10.4236/ojped.2017.72013

Received: May 12, 2017

Accepted: June 20, 2017

Published: June 23, 2017

Copyright $\odot 2017$ by authors and Scientific Research Publishing Inc. This work is licensed under the Creative Commons Attribution International License (CC BY 4.0).

http://creativecommons.org/licenses/by/4.0/ (c) (i) Open Access

\begin{abstract}
Introduction: Neonatal asphyxia is a major cause of infant morbidity in Cameroon. The aim of this study was to describe the short-term neurological outcome of children following neonatal Hypoxic-ischemic encephalopathy (HIE). Methodology: We conducted a retrospective cohort study from May 2010 to September 2013. We included 39 exposed cases against 78 non-exposed cases followed-up for at least 9 months. The variables studied were: age, sex, head circumference, neurological sequelae, postural anomalies and motor skills and developmental age/quotient. The data collected were analyzed using Epi info software version 3.5.3. The Fisher Exact Test was used to compare the variables with a significance threshold defined for $p<0.05$. Results: We recruited 39 cases for 78 controls. The majority (74.40\%) of cases were classified as HIE Sarnat 3 and $25.60 \%$ Sarnat 2. Most of the children were aged 12 - 36 months with a mean age of 18 months. The male sex was predominant with a sex ratio of 1.2 ; and $61.50 \%$ of children with HIE had head circumference < -2 Zscore. Thirtyone (79.50\%) of the exposed cases developed a handicap against $2(2.60 \%)$ in the control group. The handicaps were $61.54 \%$ severe, $10.26 \%$ moderate and $7.70 \%$ mild. The main sequelae were mental retardation (66.70\%), cerebral palsy (46.20\%) and epilepsy (30.80\%). The associated anomalies were microcephaly and bucco facial dyspraxia. The neurosensory disorders consisted of blindness (41\%), oculomotor disorders (18\%) and deafness (7.70\%). The mean developmental quotient in the cases was $49.59 \%$. Conclusion: The frequency of neurological sequelae following HIE was high in our series. Efforts should be made to prevent perinatal asphyxia and to ensure the availability of material and staff trained to help babies' breath in all the delivery rooms in our maternities.
\end{abstract}




\section{Keywords}

Hypoxic-Ischemic Encephalopathy, Cerebral Palsy, Mental Retardation, Cameroon

\section{Introduction}

Neonatal asphyxia is defined as the failure to establish or initiate normal breathing at birth [1]. It is a common cause of severe permanent neurological damage in children. The incidence of neonatal asphyxia remains high worldwide and it reflects the standard of health care in different countries. There are on average 36 to 240 cases per 1000 live births in developing countries, compared to 6 - 46 per 1,000 live births in developed countries [2]. In Cameroon, the incidence varies from 18.6 to 113 per 1000 live births and perinatal asphyxia is the third cause of neonatal mortality after infection and complications of preterm births [3] [4]. For this reason perinatal asphyxia remains a real public health problem in our setting.

The consequences of perinatal asphyxia are devastating as survivors present various neurodevelopmental problems with heavy financial, emotional and physical burden on victims and their families. Epidemiological studies in developed countries indicate that perinatal asphyxia is the cause of $8 \%-15 \%$ of cerebral palsy [5] [6]. Nguefack et al. in 2013 in Cameroon described neonatal asphyxia as the first cause of mental retardation in children between $5-72$ months of age [7]. Larbi et al. in Algeria found that almost half of the survivors from perinatal asphyxia developed moderate to severe handicap [8]. The consequences of this pathology on the development of the child described in literature include: Cerebral palsy, mental retardation, epilepsy and visual anomalies [5] [6] [7] [8] [9].

In 2013 at the Yaoundé Gyneco-Obstetric and Pediatric Hospital (YGOPH), Chiabi et al. found that $81.1 \%$ of neonates admitted for neonatal asphyxia survived, and $12.2 \%$ survived with neurological complications [4]. We carried out this study to describe the outcome of these children after discharge; with the hypothesis that they had no neurological sequelae by one year of age.

\section{Methodology}

We conducted a retrospective cohort study over a period of 41 months extending from May 2010 to September 2013. Consecutive sampling of children with a history of perinatal asphyxia and followed-up in the pediatric neurology unit of the YGOPH was used.

The YGOPH is one of the university teaching hospitals in the city of Yaoundé. The pediatric department is made up of a neonatology unit, pediatric neurology, pneumology, malnutrition, general pediatrics, out patient and immunization clinics. Any patient discharged from the hospital after a period of hospitalization 
is followed up at the outpatient department by pediatricians.

We defined exposed cases as all children born at term ( $\geq 37$ weeks of gestation) with an Apgar score $<7$ at the $5^{\text {th }}$ minute after birth, with convulsion and/or a coma; classified as Sarnat 2 or 3 and followed up for at least 9 months in the Pediatric Neurology unit.

Was considered to be at Sarnat stage 2, any newborn with an Apgar score of $<7$ at the $5^{\text {th }}$ minute after birth, lethargic/obtunded, with weak primitive reflexes and convulsions. And as Sarnat stage 3, all Newborns with an Apgar score $<7$, in a state of status epilepticus and/or Coma.

The controls were babies born at term ( $\geq 37$ weeks of gestation) with Apgar scores $>7$ at the $5^{\text {th }}$ minute of life, were hospitalized in the neonatology unit with a diagnosis other than asphyxia and then followed up at the YGOPH for at least 9 months. The controls were randomly selected from the outpatient and immunization services. They were matched to the exposed for age, sex and place of birth with a ratio of 1:2. Excluded, were all children whose parents refused to adhere to the study and/or lost to follow up.

The following variables were studied: Age, degree of Hypoxic-Ischemic Encephalopathy (HIE) according to Sarnat's classification, head circumference, developmental age estimated using the Denver test, developmental quotient, Neurological sequelae, postural and motor anomalies.

\subsection{Procedure}

Data collection was done in three steps:

Step 1: We looked for the history of perinatal asphyxia and the clinical evaluation of each child in the group of exposed cases according to the evaluation of the pediatric neurologist at 6 weeks, 3 months, 6 months, 9 months, 12 months, 18 months, 24 months.

Step 2: The children were examined with particular emphasis on neurological examination: measuring the head circumference, noting anomalies of postures, motor skills, neurosensory and cognitive impairments.

Step 3: Using tools for neurological examination, we determined the level of psychomotor development of each child based on the 4 domains of Denver test (language, gross motor skills, fine motor skills, social contact). The average score from the data collected was used to calculate the developmental age and then the developmental quotient (D. Q.) according to the following formula:

D. Q. $=($ Developmental age/Actual age $) \times 100$.

The patients were classified using the Amiel-tison classification as mild, moderate and severe handicap.

\subsection{Data Analysis}

The data collected was analyzed using Epi info version 3.5.3. The Fisher Exact test was used to compare variables with a significance threshold defined for $p<$ 0.05 . The odds ratio and its $95 \%$ confidence interval were used to establish the association between the variables. 


\subsection{Ethical Considerations}

The authorization for this study was obtained from the Institutional Committee for Ethics of Research for Human Health (ICERHH) of the Yaoundé GynecoObstetric and Pediatric Hospital. Informed consent from parents was obtained prior to their inclusion in the study.

\section{Results}

During the study period, 3040 newborns were admitted in the neonatal unit of the YGOPH and 146 newborns were diagnosed with perinatal asphyxia complicated with hypoxic-ischemic encephalopathy classified as Sarnat 2 or 3. Ninety-nine (67.8\%) were discharged alive and 44 (28.2\%) died during hospitalization. Forty-three were regularly followed up, linfant died from chocking at the age of nine months, 3 refused to participate in the study and 39 were included in the study. They were seen and examined alongside 78 patients in the control group; in a case/control ratio of 1:2.

Twenty-nine (74.4\%) were classified, as Sarnat $3 \mathrm{HIE}$, and ten (25.6\%) Sarnat 2. All the children classified Sarnat 3 presented with convulsions in the neonatal period versus $90 \%$ of those classified as Sarnat 2 .

The majority of the children (70\%) were aged between 12 - 36 months and the mean age was 18 months (range: 9 - 36 months). Boys were more represented than girls with a sex ratio of 1.2 in both groups.

The two curves for the evolution of the head circumference were fused from birth to 6 weeks of life and there after the curves separated; the curve of the head circumference for children without HIE evolved above that of children with HIE (Figure 1). Extrapolated on the standard WHO growth curves, $61.50 \%$ of exposed children had head circumference $<-2$ Zscore compared to the control group where all the children had head circumference within the normal range (between -1 Zscore to 1 Zscore).

Of the 39 cases, 31 (79.5\%) had disabilities compared to $2(2.6 \%)$ in the control group. These two were admitted for neonatal sepsis and jaundice. The difference was statistically significant. $\left(\mathrm{OR}=147.25, \mathrm{CI}_{95}(29.5861-732.8631), \mathrm{P}\right.$ : 0.0001). Most of the infants (61.54\%) had severe disability. However, 2 children with HIE Sarnat 3 and 6 children classified Sarnat 2 did not develop a disability (Table 1).

The main sequelae were mental retardation, cerebral palsy, epilepsy, buccofacial dyspraxia and neurosensory anomalies (Table 2).

The different types of mental retardation found were $50 \%$ profound, $23 \%$ severe, $15 \%$ moderate and $12 \%$ mild retardation. The main clinical types of cerebral palsy found were $89 \%$ spastic tetraplegia, $6 \%$ spastic diplegia, and $5 \%$ infantile cerebral hemiplegia.

The sequelae were predominantly found in children with severe Hypoxicischemic encephalopathy classified Sarnat 3. We did not find any Cerebral Palsy, epilepsy and bucco-facial dyspraxia in the group classified Sarnat 2 (Table 3). 


\section{Evolution of head circumference with age (months) in study group.}

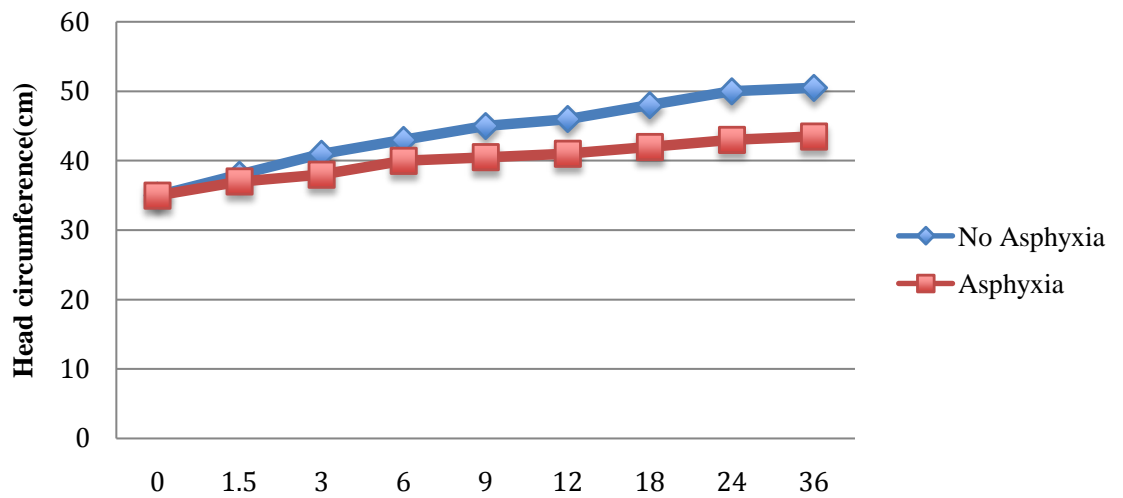

Figure 1. The evolution of the head circumference of children with HIE compared to the control group.

Table 1. Classification of disability according to degree of $\operatorname{HIE}(\mathrm{N}=39)$.

\begin{tabular}{cccc}
\hline & \multicolumn{3}{c}{ STAGE OF HYPOXIC-ISCHEMIC ENCEPHALOPATHY. } \\
\cline { 2 - 4 } DEGREE OF HANDICAP. & Sarnat 2 & Sarnat 3 & Total \\
\cline { 2 - 4 } & $\mathrm{N}(\%)$ & $\mathrm{N}(\%)$ & $\mathrm{n}(\%)$ \\
\hline Severe & $2(20)$ & $22(75.86)$ & $24(61.54)$ \\
Moderate & $1(10)$ & $3(10.34)$ & $4(10.26)$ \\
Mild & $1(10)$ & $2(6.90)$ & $3(7.70)$ \\
No handicap & $6(60)$ & $2(6.90)$ & $8(20.50)$ \\
Total n (\%) & $10(100)$ & $29(100)$ & $39(100)$ \\
\hline
\end{tabular}

Table 2. Major neurological sequelae found in children born with HIE.

\begin{tabular}{ccc}
\hline SEQUELAE & FREQUENCY & PERCENTAGE (\%) \\
\hline Mental retardation $(\mathrm{n}=39)$ & 26 & 66.7 \\
Cerebral palsy $(\mathrm{n}=39)$ & 18 & 46.20 \\
Epilepsy $(\mathrm{n}=39)$ & 12 & 30.80 \\
Microcephaly $(\mathrm{n}=39)$ & Associated anomalies & 61.50 \\
Bucco facial dyspraxia $(\mathrm{n}=39)$ & 24 & 25.60 \\
& 10 & \\
Blindness $(\mathrm{n}=39)$ & Neuro-sensory anomalies & 41.00 \\
Nystagmus $(\mathrm{n}=39)$ & 16 & 2.60 \\
Strabism $(\mathrm{n}=39)$ & 6 & 15.40 \\
Deafness $(\mathrm{n}=39)$ & 3 & 7.70
\end{tabular}

There was significant delay in developmental milestones in the group of infants with HIE; for the ability to sit without support ( $\mathrm{p}=0.0358)$, stand with support $(\mathrm{p}=0.0144)$, ability to take objects $(\mathrm{p}=0.0007)$, laugh $(\mathrm{p}=0.0076)$ and eat biscuit alone $(\mathrm{p}=0.0204)$ (Table 4$)$. 
Table 3. The main sequelae according to the stage of HIE.

\begin{tabular}{ccc}
\hline SEQUELAE & $\begin{array}{c}\text { SARNAT 2 } \\
\text { N (\%) }\end{array}$ & $\begin{array}{c}\text { SARNAT 3 } \\
\text { N (\%) }\end{array}$ \\
\hline Cerebral Palsy & & $18(100)$ \\
Mental Retardation & $2(7.7)$ & $24(92.3)$ \\
Epilepsy & & $12(100)$ \\
Bucco Facial Dyspraxia & & $10(100)$ \\
Microcephaly & $4(16.7)$ & $20(83.3)$ \\
\hline
\end{tabular}

Table 4. The average age of psychomotor acquisitions in children with HIE.

\begin{tabular}{|c|c|c|c|}
\hline \multirow[t]{2}{*}{$\begin{array}{l}\text { DEVELOPMENTAL } \\
\text { MILESTONE. }\end{array}$} & \multicolumn{3}{|c|}{ AGE OF ACQUISITIONS IN } \\
\hline & $\begin{array}{c}\text { HIE } \\
(\mathrm{M} \pm \mathrm{SD})\end{array}$ & $\begin{array}{l}\text { No HIE } \\
(\mathrm{M} \pm \mathrm{SD})\end{array}$ & $\mathrm{P}$ \\
\hline Sit with support & $8.9(4.8)$ & $6.7(1.9)$ & 0.0358 \\
\hline walking & $15(0.0)$ & $12.7(2.1)$ & 0.1829 \\
\hline Standing with support & $14.9(6.7)$ & $10.0(1.7)$ & 0.0144 \\
\hline Climb stairs & - & 21.4 & \\
\hline Throw a ball & $36(0.0)$ & $20.0(3.8)$ & 0.0813 \\
\hline Try to take objects & $10(7.4)$ & $5.2(1.0)$ & 0.0007 \\
\hline Pintching & $13.5(2.1)$ & $14.6(2.5)$ & 0.6105 \\
\hline scketch & $19(0,0000)$ & $21.8(2,3)$ & 0.1189 \\
\hline Laugh & $6.4(5.0)$ & $3.4(1.0)$ & 0.0076 \\
\hline Papa maman & $17.8(9.0)$ & $11.2(1.7)$ & 0.1498 \\
\hline $\begin{array}{c}\text { Three words besides } \\
\text { papa maman }\end{array}$ & $17(0.0)$ & $17.7(3.6)$ & 0.7427 \\
\hline Points to body parts & 26 & 21.4 & 0.0789 \\
\hline Obeys order & $26(0.0)$ & $22(2.7)$ & 0.0690 \\
\hline Spontaneous smile & $7.2(6.5)$ & $4.7(1.2)$ & 0.5883 \\
\hline Eats biscuit alone & $10.9(5.9)$ & $7.4(1.5)$ & 0.0204 \\
\hline Avoid strangers & $14.5(6.6)$ & $9.9(1.3)$ & 0.0756 \\
\hline Imitate domestic tasks & - & 19.4 & \\
\hline Undress & - & 21.4 & \\
\hline Use spoon correctly & - & 22.8 & \\
\hline
\end{tabular}

The mean developmental quotient (DQ) for children with HIE at birth was $49.59 \%$.

\section{Discussion}

The aim of this study was to describe the short-term post-discharge neurological outcome of infants who survived hypoxic-ischemic encephalopathy classified Sarnat 2 or 3 . We analyzed the data of 39 infants. The weaknesses of this study are in relation to its retrospective nature and the challenges associated with po- 
verty in a source-limited setting. Health care in our setting is very costly despite the extreme poverty of the population. The patient and family pay for everything from consultation to complimentary investigations and treatment. It was difficult to carry out all investigations needed to make exact diagnosis of asphyxia and its consequences on the neurodevelopment of the victims. It was impossible for us to carry out biochemical tests including blood gazes, kidney and liver function tests coagulation profile, Electroencephalograms, as well as CT scan and Magnetic Resonance Imagery to confirm the diagnosis of perinatal asphyxia and its modifications on the morphology of the brain of victims. Therefore, the diagnosis of asphyxia was based on the Apgar score $<7$ at the $5^{\text {th }}$ minute of life (which is dependent on experience/knowledge of birth attendant) and the clinical assessment of the severity of Hypoxic-ischemic encephalopathy. These could reduce the strength of our results. Secondly, the large number of patients lost to follow-up reflects the challenges we face with post discharge follow up of patients in our setting and could be a major shortcoming to our study. In fact the patients received in our unit come from all over the region with very far distances to cover, together with the fact that consultation fees is paid for each visit. These could contribute to the non-respect of appointments, so that most often only serious cases make the extra effort to respect appointments. On the other hand, there is the traditional believe that children with neurodevelopmental problems are under the influence of witch craft or some evil spirits, motivating parents to prefer spiritualists and pastors instead of visiting the hospital. Despite these limitations, this study reveals the impact of HIE on infant morbidity and mortality in our context.

There was significant delay in the developmental milestones in the group of children born with HIE compared to children born without. Asphyxia results in an energy deficit which causes the shutdown of membrane pumps; The resulting ionic imbalance triggers various catabolic processes which lead to the death of brain cells responsible for the deficits [10]. Children born with moderate or severe asphyxia probably develop more severe brain lesions, as was the case in this cohort, where nearly three-quarters of the subjects had a history of severe Hypoxic-ischemic encephalopathy.

The majority of children with disabilities were between 12 and 36 months of age. This finding is similar to that of Shah et al. in Canada in 2006 [11]. At the age of one year the cerebral structures are more developed and allows for a better appreciation of the clinical manifestations [12] [13]. This could explain the free interval and justify the diagnosis of most of the disability after the age of 12 months.

There were more male children with disabilities (52\%). Begum et al. also found a predominance of the male sex with $69 \%$ against $31 \%$ of females [14]. This could be explained by the fact that estrogens influence the development of the brain of the female fetus and the newborn and promote protection against ischemic lesions. In addition, there is a neurobiological difference between neurons in males and females resulting in a difference in responses when brain le- 
sions occur [10].

Of the 39 survivors from moderate to severe HIE, 31 (79.5\%) had a disability against $2(2.6 \%)$ in the control group. This result is similar to that of Marlow et al. in the United Kingdom, who found that $76.9 \%$ of a cohort of children followed for Hypoxic-ischemic encephalopathy had disabilities [15]. Shah et al. in Canada found that $70 \%$ of children in their cohort had an unfavorable neurological outcome, with $66 \%$ developing severe disability [11]. The rate of disability in our cohort is higher than that of Gonzalez de Dios et al. in Spain, who found an incidence of neurological sequelae of $16.5 \%$ [16]. Compared to studies in other developing, the incidence of disability in our series is higher than the $60 \%$ reported by Begum et al. in Dhaka (Bangladesh) [14] and compared to African studies, the rate of disability in children born with asphyxia is higher than that of Halloran et al. in Zambia, who found 31\% disability in children born with asphyxia compared to $9 \%$ in children born without asphyxia. The children born with asphyxia were 4.4 times more likely to have an abnormal neurological examination than children born without asphyxia [17]. While Larbi in Algeria found that almost half the children in his cohort developed severe handicap [8]. This high rate of disability in our series may be due to the fact that YGOPH being a reference hospital receives a high number of high-risk labor cases and babies with perinatal asphyxia from other health facilities. The high rate of disabilities could also be linked to the fact that all the children included in our study were classified as Sarnat stage 2 or 3 and not only based on poor Apgar score as most of the studies cited above. Another reason for the high rate of handicap in our series could be that most (55\%) of the infants diagnosed with HIE did dot respect their post discharge appointments. In our context parents do not take their children to hospital when the children look physically well, this leaves us with the believe that those who respected the appointments with the pediatric neurologist were those with anomalies while those who did not respect the appointments were those who did not have any visible anomaly, so were of no worry to the parents.

Out of the 31 infants who had an adverse outcome, $61.54 \%$ of the patients had severe disabilities. This result is similar to that of Shah et al. in Canada, who also showed a predominance of severe disability [11] while Begum in his study found, on the contrary, $27.77 \%$ severe handicap, $33.33 \%$ moderate handicap and $38.88 \%$ mild handicap [14]. González de Dios in Spain reported 21\% of severe sequelae, $21 \%$ of moderate sequelae and $57.89 \%$ of minor sequelae [16]. In Algeria, Larbi reported that $49 \%$ of victims of neonatal asphyxia developed severe handicap [8]. The differences between our results and those of other authors may be justified by the lack of similarity in the method of diagnosis of perinatal asphyxia. In our cohort, no biological analyses were done to confirm diagnosis of perinatal asphyxia but diagnosis was based on the $5^{\text {th }}$ minute Apgar score and the clinical neurologic state of the children.

The main sequelae were mental retardation (66.7\%), Cerebral Palsy (46.20\%) and epilepsy. In the study carried out by González de Dios, cerebral palsy was 
the main sequel, and other disabilities such as mental retardation, epilepsy and sensory deficits were rare [16]. Shah et al. found 32\% cerebral palsy, $1.8 \%$ isolated mental retardation [11] while Marlow et al. reported 22\% Cerebral Palsy, $13 \%$ of hearing loss and $6.6 \%$ of blindness [15]. The high rate of Cerebral Palsy indicates that asphyxia-related lesions occur on a growing immature brain.

Mental retardation was found in $66.7 \%$ of our study population. A significant proportion of survivors of moderate or severe anoxic-ischemic encephalopathy without sensory/motor sequelae have cognitive and/or attention deficit disorders. This rate is high compared to that of Nguefack et al. in 2013 at YGOPH, who found that Hypoxic-ischemic encephalopathy represented $41.8 \%$ etiologies of mental retardation [7]. This difference may be related to the selection criteria of the study groups. Our cohort consisted only of children born with moderate to severe Hypoxic-ischemic encephalopathy, so there was a greater possibility of having a higher rate of mental retardation. Deep mental retardation was predominant. This could be related to cortico-subcortical lesions frequently described in perinatal asphyxia [18].

Thirty percent of children with epilepsy in our study population had all convulsed during the neonatal period. According to Da Silva et al. [19] neonatal convulsions are associated with a high incidence of postnatal epilepsy.

Spastic tetraplegia was the most frequent type (89\%) of cerebral palsy in our patients. Thornberg et al. found 50\% tetraplegia and 50\% spastic diplegia [2]. Marlow found 53\% tetraplegia, $6.7 \%$ diplegia and $40 \%$ hemiplegia [15]. The predominance of spastic tetraplegia in all these studies could be explained by the fact that the main anatomical lesion in cerebral hypoxia is periventricular leucomalacia with bilateral involvement of the pyramidal tract [5] [18] [20].

The frequency of microcephaly was $61.5 \%$ in children born with asphyxia. This result is similar to that of Shah et al., who found a frequency of $51.3 \%$ in their cohort [11]. The curves for the head circumference of children in both groups evolved together from birth up to 6 weeks of life and then separated beyond six weeks; with the curve for non exposed children evolving above that of exposed children. Referring to the standard WHO growth curves [21], 61.5\% of exposed cases had head circumference lower than -2 Zscore compared to none in the control group. Although it was not possible for MRI to be performed on our patients, the microcephaly may be due to cerebral atrophy following Hypoxic-ischemic damage described in perinatal asphyxia. During the first weeks of life, the size of the brain remains relatively stable until healing, scarring and fibrosis of damaged brain cells occurs later. The effects cannot be clinically demonstrated during the first weeks of life and only become visible as the child grows older. [18] [20] [22] [23] [24].

\section{Conclusions}

The occurrence of post-asphyxia neurological sequelae is high in our series and especially in children with severe Hypoxic-ischemic encephalopathy. The main sequelae were mental retardation, Cerebral Palsy and epilepsy. The associated 
anomalies were microcephaly and bucco facial dyspraxia. The neurosensory disorders consisted of blindness, oculomotor disorders and deafness.

Considering the devastating effects of Hypoxic-ischemic injury on the neurodevelopment of victims as well as the cost of care, more effort must be made in the prevention of perinatal asphyxia. Improving antenatal care, equipping delivery rooms with adequate material to help babies' breath and train all birth attendants on neonatal resuscitation. The education of the parents of victims of asphyxia on the importance of the follow-up of the children could help improve the long-term developmental outcome.

\section{References}

[1] World Health Organization (1996) Perinatal Mortality: A Listing of Available Information. WHO, Geneva.

[2] Thornberg, E., Thiringer, K., Odeback, A. and Milsom, I. (1995) Birth Asphyxia: Incidence, Clinical Course and Outcome in a Swedish Population. Acta Pædiatrica, 84, 927-932. https://doi.org/10.1111/j.1651-2227.1995.tb13794.x

[3] Monebenimp, F., Tietche, F. and Eteki, N. (2005) Asphyxie neonatale au centre hospitalier et Universitaire de Yaounde, Cameroun. Clinics in Mother and Child Health, 2, 335-358.

[4] Chiabi, A., Nguefack, S., Mah, E., Nodem, S., Mbuagbaw, L., Mbonda, E., et al. (2013) Risk Factors for Birth Asphyxia in an Urban Health Facility in Cameroon. Iranian Journal of Child Neurology, 7, 46-54.

[5] Badawi, N., Felix, J.F., Kurinczuk, J.J., Dixon, G., Watson, L., Keogh, J.M., et al. (2005) Cerebral Palsy Following Term Newborn Encephalopathy: A PopulationBased Study. Developmental Medicine \& Child Neurology, 47, 293-298. https://doi.org/10.1017/S0012162205000575

[6] Blair, E. and Stanley, F.J. (1998) Intrapartum Asphyxia: A Rare Cause of Cerebral Palsy. The Journal of Pediatrics, 112, 515-519.

https://doi.org/10.1016/S0022-3476(88)80161-6

[7] Nguefack, S., Kamga, K.K., Moifo, B., Chiabi, A., Mah, E. and Mbonda, E. (2013) Causes of Developmental Delay in Children of 5 to 72 Months Old at the Child Neurology Unit of Yaounde Gynaeco-Obstetric and Paediatric Hospital (Cameroon). Open Journal of Pediatrics, 3, 279-285. https://doi.org/10.4236/ojped.2013.33050

[8] Larbi, D.B., Boukhelal, H., Chaou, M., Bouzerar, Z. and Mozouni, S.M. (1996) Asphyxie néonatale et devenir à long terme. Archives de Pédiatrie, 3, S410. https://doi.org/10.1016/0929-693X(96)86282-8

[9] Zupan-Simunek, V., Razafimahefa, H. and Caeymaex, L. (2008) Asphyxie per-partum du nouveau-né à terme-Pronostic neurologique des asphyxies périnatales à terme. http://www.em-consulte.com/en/article/114908

[10] Johnston, M.V. and Hagberg, H. (2007) Sex and the Pathogenesis of Cerebral Palsy. Developmental Medicine \& Child Neurology, 49, 74-78. https://doi.org/10.1017/S0012162207000199.x

[11] Shah, P.S., Beyene, J., To, T., Ohlsson, A. and Perlman, M. (2006) Post Asphyxial Hypoxic-Ischemic Encephalopathy in Neonates: Outcome Prediction Rule within 4 Hours of Birth. Archives of Pediatrics and Adolescent Medicine, 160, 729-736. https://doi.org/10.1001/archpedi.160.7.729

[12] Barkovich, A.J.B., Latal, B., Vigneron, D., Sola, A., Partridge, J.C., Allen, F., et al. 
(1998) Prediction of Neuromotor Outcome in Perinatal Asphyxia: Evaluation of MR Scoring Systems. American Journal of Neuroradiology, 19, 143-149.

[13] Perlman, M. and Shah, P.S. (2011) Hypoxic-Ischemic Encephalopathy: Challenges in Outcome and Prediction. The Journal of Pediatrics, 158, e51-e54. https://doi.org/10.1016/j.jpeds.2010.11.014

[14] Begum, H.A., Rahman, A., Anowar, S., Mortuza, A. and Nahar, N. (2006) Long Term Outcome of Birth Asphyxiated Infants. Mymensingh Medical Journal, 15, 6165.

[15] Marlow, N., Rose, A.S., Rands, C.E. and Draper, E.S. (2005) Neuropsychological and Educational Problems at School Age Associated with Neonatal Encephalopathy. Archives of Disease in Childhood. Fetal and Neonatal Edition, 90, F380-F387. https://doi.org/10.1136/adc.2004.067520

[16] González de Dios, J. and Moya, M. (1996) Perinatal Asphyxia, Hypoxic-Ischemic Encephalopathy and Neurological Sequelae in Full-Term Newborns. II. Description and Interrelation. Revista De Neurologia, 24, 969-976.

[17] Halloran, D.R., McClure, E., Chakraborty, H., Chomba, E., Wright, L.L. and Carlo, W.A. (2008) Birth Asphyxia Survivors in a Developing Country. Journal of Perinatology, 29, 243-249. https://doi.org/10.1038/jp.2008.192

[18] Grow, J. and Barks, J.D.E. (2002) Pathogenesis of Hypoxic-Ischemic Cerebral Injury in the Term Infant: Current Concepts. Clinics in Perinatology, 29, 585-602. https://doi.org/10.1016/S0095-5108(02)00059-3

[19] Da Silva Garcias, L.F., Nunes, M.L. and Da Costa, J.C. (2004) Risk Factors for Developing Epilepsy after Neonatal Seizures. Pediatric Neurology, 30, 271-277. https://doi.org/10.1016/j.pediatrneurol.2003.09.015

[20] Mercuri, E., Ricci, D., Cowan, F.M., Lessing, D., Frisone, M.F., Haataja, L., et al. (2000) Head Growth in Infants with Hypoxic-Ischemic Encephalopathy: Correlation with Neonatal Magnetic Resonance Imaging. Pediatrics, 106, 235-243. https://doi.org/10.1542/peds.106.2.235

[21] World Health Organization, Multicenter Growth Reference Study Group (2006) WHO Child Growth Standards: Length/Height-for-Age, Weight-for-Age, Weightfor-length, Weight-for-Height and Body Mass Index-for-Age: Methods and Development. World Health Organization, Geneva, 312.

[22] Amiel-Tison, C. and Ellison, P. (1986) Birth Asphyxia in the Fullterm Newborn: Early Assessment and Outcome. Developmental Medicine \& Child Neurology, 28, 671-682. https://doi.org/10.1111/j.1469-8749.1986.tb03914.x

[23] Robertson, C.M. and Finer, N.N. (1993) Long-Term Follow-Up of Term Neonates with Perinatal Asphyxia. Clinics in Perinatology, 20, 483-500.

[24] Rennie, J.M., Hagmann, C.F. and Robertson, N.J. (2007) Outcome after Intrapartum Hypoxic Ischaemia at Term. Seminars in Fetal and Neonatal Medicine, 12, 398407. https://doi.org/10.1016/j.siny.2007.07.006 
Submit or recommend next manuscript to SCIRP and we will provide best service for you:

Accepting pre-submission inquiries through Email, Facebook, LinkedIn, Twitter, etc. A wide selection of journals (inclusive of 9 subjects, more than 200 journals)

Providing 24-hour high-quality service

User-friendly online submission system

Fair and swift peer-review system

Efficient typesetting and proofreading procedure

Display of the result of downloads and visits, as well as the number of cited articles Maximum dissemination of your research work

Submit your manuscript at: http://papersubmission.scirp.org/

Or contact ojped@scirp.org 